\title{
Health Impact Economic Cost Due to Climate Change Over Three European Cities
}

\author{
Roberto San José ${ }^{1}$ Juan L. Pérez ${ }^{1}$, Libia Pérez ${ }^{1}$, Rosa Maria Gonzalez Barras ${ }^{2}$, \\ Julia Pecci ${ }^{3}$ and Marino Palacios ${ }^{3}$
}

\begin{abstract}
We have studied the cost of health impacts of two possible IPCC global climate scenarios (RCP 4.5 and RCP 8.5) on mortality and morbidity related with changes in the temperature and air pollution concentrations for years 2011, 2030, 2050 and 2100. The health outcomes are based on dynamical downscaled information with very high spatial resolution 50 meters. Short term health impacts were assessed for ozone, particles, apparent temperature and heat waves. Future changes in these environmental exposure variables as simulated by the model system for future years and compared relative to conditions in the 2011. Concentration-response coefficients were taken from the recent environmental epidemiological literature. The morbidity and mortality costs arising from climate change are then evaluated for each health outcome separately by multiplication of the number of cases with the respective cost estimates. For the mortality we use the Value of a Statistical Life and for the morbidity the cost of illness. We present the most significate results for each city. We have results of cost attributed to the climate change every 50 meters grid cell. The larger increase of costs of mortality and morbidity was noted in the increasing scenario (RCP8.5) for year 2100, because RCP 8.5 is characterized by temperature increments. As summary, Madrid will be the city more affected by the climate change with a cost of the health of $5.35 \mathrm{~K} \$ / \mathrm{m} 2$, the next is Milan $1.65 \mathrm{~K} \$ / \mathrm{m} 2$ and finally London with $0.99 \mathrm{~K} \$ / \mathrm{m} 2$. But the results have shown how the costs could be very different from one street to other. Maps of the spatial distribution of the costs of the climate change have showed.
\end{abstract}

Keywords - Health, Cost, Climate, Downscaling.

\section{INTRODUCTION}

$\mathrm{M}$ ANY chronic diseases, especially those of the respiratory and cardiovascular systems, worse during or after a period with adverse and / or high concentrations of pollutants weather conditions. Previous studies have shown how air pollutants and extreme temperatures affect human health by modifying the rates of mortality and morbidity [1]. Managing the effects of climate change on health locally in a great challenge that should help the scientific community [2]. Changes in the global climate have complex effects in urban areas. Urban areas are the areas where the local response to global change is more pronounced [3], recent studies have

\footnotetext{
${ }^{1}$ Environmental Software and Modelling Group, Computer Science School, Technical University of Madrid (UPM),

Madrid, Spain

${ }^{2}$ Department of Physics and Meteorology, Faculty of Physics, Complutense University of Madrid (UCM), Ciudad Universitaria, 28040 Madrid, Spain

${ }^{3}$ Indra S.A., C/ Mar Egeo, 4, Pol. Industrial 1, 28830 San Fernando de Henares, Madrid (Spain)
}

suggested that global climate change will have a significant impact on both the local climate and air quality urban [4]. Global climate models (GCMs) are increasing their spatial resolution, but are not yet suitable for analysis of the health problems caused by climate change to urban scales. Local weather patterns and air pollution are heavily influenced by topography, land use, buildings, etc. So the studies of urban areas need information very high resolution to capture the high spatial and temporal variability of air pollution in a city [5] . In previous studies on climate change and human health, they have been used projections of global climate models (GCM) or regional climate models (RCM) [6], [7] and [8]. However, few studies have used the results of dynamic scale reduction with very high spatial resolution to analyse local health impacts of climate change for cities. Global climate impacts on human health in urban areas that combine extreme events in temperature and air pollution are poorly understood and this work focuses on them as well as their economic impact. Last developments in computer science and atmospheric science, particularly in the use of dynamical downscaling techniques provide opportunities to investigate climate-air pollutionrelated health consequences at city levels [9]. Quantifying potential air pollution-climate related health effects requires weather and air quality models working together to predict future air pollution levels based on climate model results and taking into account the feedback effects, before they can be linked to health impacts functions and economic models. Estimating the health impacts of air pollution and climate change involves linking climate, air quality and health projections. We have chosen a dynamical downscaling process, using models of climate and air quality high resolution both regional and urban level, including a model of computational fluid dynamics (CFD) to take into account the effects of buildings, ventilation effects and shade given in a city. The atmospheric flow and microclimate on urban areas are influenced by the urban characteristics, and improve atmospheric turbulence, as well as modify the turbulent transport, dispersion and deposition of air pollutants [10]. In past research works, we have presented the impacts of the global climate on urban meteorological conditions and air pollution concentrations [11] and now we will use these results as input to the health impact and economic model to assess the potential future changes of mortality and morbidity and theirs respective economic costs over three different cities: London, Madrid and Milan. It is very useful to estimate the health costs of climate change in monetary terms. Estimates of the economic costs can be used in cost-benefit analysis for the 
comparison of adaptation strategies [12].

\section{METHODOLOGY}

To estimate the economic cost of health impacts due to climate change, the first step is to estimate future climate change impacts on human mortality and morbidity due to increased heat and changes in air pollution concentrations,. We use future climate data, and air pollution concentration with very high spatial resolution. For air quality projections, the approach was to run simultaneously the projected climate information and the air quality numerical model while holding future air pollution emissions constant. We use result with 50 meters of spatial resolution and one hour of temporal resolution for years 2011, 2030, 2050 and 2100 from a dynamical downscaling process. We made use of a single year of simulated meteorology and air quality in this study to capture peak events that may have been moderated or lost from a statistical average over successive years. The assessments consider the projected impacts of climate change considering three future years 2100, 2050 and 2030 against the baseline situation 2011. The description of the dynamical downscaling method was published already, for detailed information; refer to publication [13]. Future projections of $\mathrm{O} 3$ and PM have been chosen because of their importance to public health from the air quality point of view [14] and heat waves and apparent temperature from the meteorological point of view. In the simulations we have used boundary conditions from two Representative Concentration Pathways (RCPs), RCP 4.5 and RCP 8.5 defined by the IPCC (Intergovernmental Panel on Climate Change) institution in the Fifth Assessment Report (AR5). The IPCC report [15] identifies up to four climate scenarios, from very strong mitigation scenarios (nonrealistic) (RCP2.6) to a business-as-usual scenario (RCP 8.5). The two selected global climate scenarios are the most used by the scientific community because they represent relatively low and high greenhouse gas projections/radiative forcing respectively. Also, the choice of the worst-case scenario (RCP 8.5) and the best-realistic-case scenario (RCP 4.5) was motivated by the goal of displaying extreme changes that can be forecasted at city scale to allow implementing mitigation and adaptation strategies. The RCP 4.5 assumes a scenario where radiative forcing stabilizes at $4.5 \mathrm{~W} / \mathrm{m} 2$ by the year 2100 [16]. This corresponds to an increase in average global temperature of about three degrees centigrade. The RCP 8.5, on the other hand, is an extreme (or worst case) scenario where very little mitigation actions are taken by countries to thwart future climate change. This corresponds to a scenario which has the highest greenhouse gas emissions and may lead to an increase in average temperatures up to six degrees centigrade [17].

\section{A. Health impacts}

The first step is developing a concentration-response function for each health outcome sensitive to the climate. This is sufficient if a relative percent change in the health outcome interest is to be estimated. However in this case, we want to know the economic costs of the impacts, so the concentrationresponse functions needs to be linked with the baseline mortality or morbidity rate and the exposed population. The equation 1 [18] is the formula applied in this study:

$$
\Delta M=K *\left(e^{\beta \Delta c}-1\right) * P
$$

Where $\Delta \mathrm{M}$ is the change in the health outcome because changes in an environmental factor(temperature or air concentrations), $\mathrm{K}$ is the baseline mortality or morbidity rate, $\beta$ is the $\log$ relative risk associated with a change in the exposure to the environmental factor which can be calculated in epidemiological studies, $\Delta \mathrm{C}$ is the estimated change in the environmental factor (future-present) and $\mathrm{P}$ is the exposed population in the present (2011). Also $\mathrm{K}$ and $\beta$ are fixed to the 2011 values to isolate only the climate impacts, so in our study uses a constant population and mortality rate over time like other studies [19]. We use gridded population distribution with 200 meters of spatial resolution which was generated under the DECUMANUS EU project. This research work is part of the project. We assume that the population will remain constant in the future periods. Using epidemiological studies which give us the relation between environmental factors and morbidity and mortality, the number of cases of morbidity and/or mortality attributed to environmental factors are determined for each of the health outcomes separately, using specific exposure-response functions. These calculations are made taking into account the differences of the environmental factors between the future and the present. The difference between the results of future and present corresponds to the cases of morbidity and mortality due to climate change. Several health effects or outcomes are calculated for mortality and morbidity: All causes mortality, cardiovascular mortality, respiratory mortality, respiratory hospital admissions and cardiovascular hospital admissions. These outcomes are for all ages, except in case of the heat waves where mortality +65 years old are calculated. The short-term health effects of the heat are analyzed based on two exposure variables: Apparent Temperature (AT) and Heat waves (HW). Only summer months (June-August) are considered to study the health effects of the heat waves days. For PM10 the exposure indicator is the daily mean and for ozone we used the daily maximum 8-hour average. Mortality and morbidity rates ( $\mathrm{K}$ in the equation 1) has been extracted from European mortality database of the WHO and the European Hospital Morbidity Database of the WHO by countries and the table 1 show the rates per 100,000 people used in this study.

TABLE I: Mortality rates for Italy, Spain and United Kingdom.

\begin{tabular}{lcccc}
\hline \hline \multicolumn{1}{c}{ Health End point } & Ages & Italy & Spain & United Kingdom \\
\hline All causes & All & 478.12 & 481.45 & 423.6 \\
mortality & +65 & 3248.73 & 3171.04 & 2774.73 \\
Cardiovascular & All & 159.79 & 132.45 & 125.77 \\
Mortality & +65 & 1256.58 & 1006.2 & 922.49 \\
Respiratory & All & 25.57 & 46.03 & 51.77 \\
$\quad$ Mortality & +65 & 223.52 & 363.42 & 403.04 \\
Cardiovascular & All & 2034.44 & 1280.96 & 1103.97 \\
Hospital admission & & & & \\
Respiratory & All & 1012.1 & 1123.63 & 946.13 \\
Hospital admission & & & &
\end{tabular}

\section{B. Monetary cost}

The morbidity and mortality costs arising from climate 
change are then evaluated for each health outcome separately by multiplication of the number of cases with the respective cost estimates. To distinguish the value of an anonymous life from the life of an identified person, the concept of "statistical life" has been adopted. The willingness-to-pay method (WTP) estimates the value of life according to the amounts that individuals are prepared to pay to reduce risks to their lives. Thus, the sum of individual willingness-to-pay indicates how much value is attributed to an improvement in security or a reduction of environmental impact by the society as a whole. Monetary estimates of changes in premature mortality risk are often expressed in terms of the Value of a Statistical Life (VSL). In particular, VSL refers to the WTP for changes in the risk of premature death aggregated over the population experiencing the risk change. This approach yields a simple result for researchers and policy-makers, which contributes to assessing the magnitude of a given problem, in terms of monetized societal value. We have available data from the meta-analysis of VSL studies and VSL values by the OECD Country-specific VSL (2010) in US\$ are: Italy, 3.0 million, Spain, 3.06 million and the UK, 3.55 million. In the case of estimating the cost of morbidity, the total value to society of an individual's avoidance of a hospital admission has a principal component: the cost of illness (COI) The Cost of Illness metric summarizes the expenses that an individual must bear for hospital admissions. The Unit values available for Hospital admissions are: Cardiovascular: \$26,123 and Respiratory:
$\$ 19,612$. Unit values are based on ICD-code-specific estimated hospital charges and the opportunity cost of time spent in the hospital (based on the average length of a hospital stay for the illness). The opportunity cost of a day spent in the hospital is estimated as the value of the lost daily wage, regardless of whether or not the individual is in the workforce. These values are used in the BENMAP software and they are based on discharge statistics provided by the Agency for Healthcare Research and Quality's Healthcare Utilization Project National Inpatient Sample (NIS) database (2007).

\section{RESULTS}

We will present the most significate results for each city. We have results of cost attributed to the climate change every 50 meters grid cell. In case of London the worst year will be 2100. The increment of the annual cost for hospital admission for year 2100 respect to the 2011 could be up to $9409.6 \$$ in the RCP 8.5 climate scenario and 7628.\$ in the RCP 4.5 for an average grid cell of the domain. For the mortality costs could be increments of $2482.5 \mathrm{~K} \$$ in RCP 8.5 and decrements of 562.7 for RCP 4.5. Heat is the environmental factor which causes these increments in the RCP 8.5 whilst in the RCP 4.5 the health effects for $\mathrm{O} 3$ exposure and number of heat waves will be decreased. A summary of the results for the year 2100, including of outcomes analysed, is shows in the table 2.

TABLE II: Monetary estimates of the 2100 annual health costs due to climate change's effects on London for 50 meters grid cells

\begin{tabular}{|c|c|c|c|c|c|c|c|c|}
\hline \multirow{2}{*}{\multicolumn{3}{|c|}{ LONDON (50 m. grid cells) }} & \multicolumn{6}{|c|}{2100} \\
\hline & & & \multicolumn{3}{|c|}{ RCP 4.5} & \multicolumn{3}{|c|}{ RCP 8.5} \\
\hline Outcome & Cause & Factor & MIN & MAX & AVG & MIN & MAX & AVG \\
\hline \multirow{4}{*}{$\begin{array}{l}\text { Hospital } \\
\text { Cost } \\
(2000 \$)\end{array}$} & Resp. & АТР90 & 0 & 4442,1 & 1362,5 & 0 & 36783,8 & 11670 \\
\hline & Resp. & PM10 & 0 & 16085,2 & 5153,9 & $-4616,4$ & 0 & -778 \\
\hline & Resp. & $\mathrm{O} 3$ & $-13104,7$ & 0 & $-4417,7$ & $-3054,8$ & 6,6 & -595 \\
\hline & Cardio & PM10 & 0 & 17278,1 & 5530,1 & $-5144,6$ & 0 & -888 \\
\hline \multirow{12}{*}{$\begin{array}{l}\text { Mortality } \\
\text { Cost } \\
(2000 \mathrm{~K} \$)\end{array}$} & All +65 & HW & $-1116,8$ & 364,1 & -245 & 0 & 2189,1 & 411,4 \\
\hline & Cardio & HW & $-331,9$ & 107 & $-72,9$ & 0 & 651,1 & 122,8 \\
\hline & Resp. & HW & $-281,3$ & 98,6 & $-61,4$ & 0 & 548,4 & 100,7 \\
\hline & All & ATMAX & 0 & 278,6 & 79,8 & 0 & 3051,1 & 963,9 \\
\hline & Cardio & ATMX & 0 & 139 & 39,7 & 0 & 1501,1 & 473 \\
\hline & Resp. & ATMAX & 0 & 179,6 & 51,1 & 0 & 1863,3 & 581 \\
\hline & All & PM10 & 0 & 1045,7 & 334,8 & $-307,3$ & 0 & $-52,6$ \\
\hline & Cardio & PM10 & 0 & 245,2 & 78,5 & $-73,5$ & 0 & $-12,7$ \\
\hline & Resp. & PM10 & 0 & 51,9 & 16,6 & $-16,1$ & 0 & $-2,9$ \\
\hline & All & $\mathrm{O} 3$ & $-1097,2$ & 0 & $-369,9$ & $-255,7$ & 0,6 & $-49,8$ \\
\hline & Cardio & $\mathrm{O} 3$ & $-699,9$ & 0 & $-235,9$ & $-160,7$ & 0,9 & $-30,6$ \\
\hline & Resp. & $\mathrm{O} 3$ & $-528,4$ & 0 & $-178,1$ & $-118,5$ & 1,4 & $-21,7$ \\
\hline
\end{tabular}

Figure 1 shows the annual total costs due to premature mortality by changes in the apparent temperature for year 2100 under two possible climate scenarios RCP 4.5 and RCP 8.5. Figure 1 shows the increment of the cost associated to the heat-related mortality by the end of the century. It is greater in the RCP 8.5 than in the RCP 4.5. The purple areas (parks and water bodies) are zones where there are not people living, so nobody is exposed to the environmental factors. The costs calculated under RCP8.5 will be near ten times as high as those calculated under RCP4.5. These findings illustrate the health impacts associated with the difference between scenarios in which greenhouse gas concentrations in the atmosphere/radiative forcing continue to increase (RCP8.5) or stabilize over time (RCP4.5), respectively. The figure shows also several hot spots where the cost of the climate change could be up to $1.2 \mathrm{~K} \$ / \mathrm{m} 2$ and zones very close to the hot spots 
where cost is only $0.5 \mathrm{~K} \$ / \mathrm{m} 2,50 \%$ less, this situation is observed along the for example the same street. These results

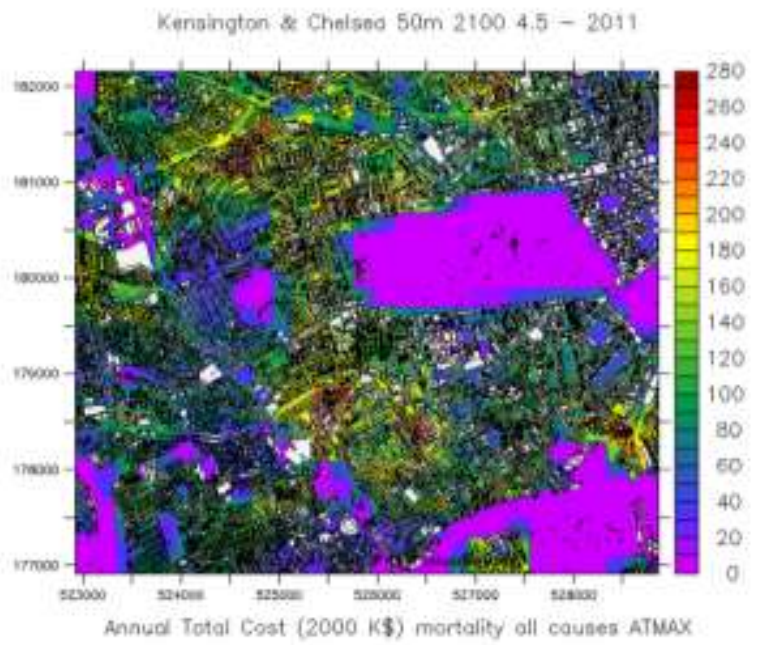

shown that it is very important to get health impacts with very high spatial resolution over urban areas.

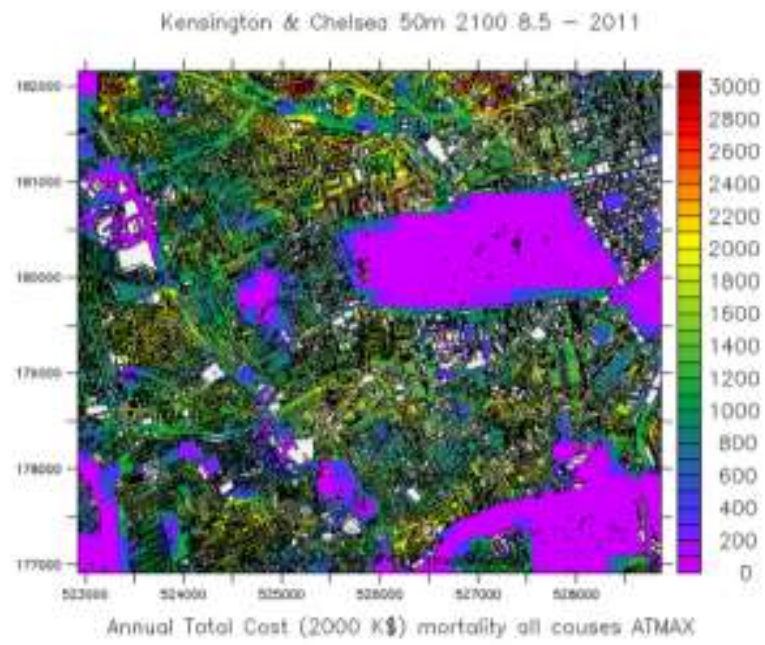

Fig 1: Spatial distribution of the differences in annual total cost (2000 K\$) mortality for 2100 respect to 2011 following RCP 4.5 (left) and RCP 8.5 (right) scenarios with $50 \mathrm{~m}$. of spatial resolution over Kensington and Chelsea.

In Milan, 2100 was not simulated. 2030 is a good year from a health point of view for both climate scenarios, but in the 2050 the costs of the health problems due to climate change will be increased. Mortality cost could be $488.8 \mathrm{~K} \$$ for RCP 4.5 and $4137,2 \mathrm{~K} \$$ for RCP 8.5 for year 2050 in an average grid cell of 50 meters of Milan. The cost of the RCP 8.5 is ten times more than the RCP 4.5, the main reason of these high costs is the increment of the temperature over Milan with the RCP 8.5. In the RCP 4.5 there will be small increments by heat, ozone and particles exposure. A summary of the results for the year 2050, including all outcomes analyzed, is shows in the table 3 .

TABLE III: Monetary estimates of the 2050 annual health costs due to climate change's effects on Milan for 50 meters grid cells.

\begin{tabular}{ccccccccc}
\hline \hline \multicolumn{2}{c}{ MILAN (50 m. grid cells) } & & \multicolumn{3}{c}{2050} & \multicolumn{2}{c}{ RCP 8.5} \\
\hline Outcome & Cause & Factor & MIN & MAX & AVG & MIN & MAX & AVG \\
& Respiratory & ATP90 & 0 & 7003,1 & 2509,8 & 0 & 29256 & 11327 \\
Hospital & Respiratory & PM10 & $-1560,9$ & 3208,5 & 207,6 & $-3951,9$ & 97,6 & -903 \\
$(2000 \$)$ & Respiratory & O3 & $-26,6$ & 85 & 10,4 & $-76,8$ & 34,5 & -13 \\
& Cardio & PM10 & -3811 & 7725 & 486,6 & $-9616,3$ & 216,3 & -2204 \\
& All +65 & Heat Waves & $-2829,6$ & 3456,1 & -49 & $-1284,2$ & 11265,6 & 649 \\
& Cardio & Heat Waves & -1272 & 1630 & $-14,4$ & $-593,8$ & 5172,3 & 297,1 \\
& Respiratory & Heat Waves & $-519,4$ & 971,1 & 24,2 & -307 & 2517,5 & 141,6 \\
Mortality & All & ATMAX & 0 & 1077,9 & 364,7 & 0 & 5922,6 & 2281 \\
Cost & Cardio & ATMX & 0 & 303,2 & 102,3 & 0 & 1670,1 & 643,6 \\
& Respiratory & ATMAX & 0 & 99,6 & 34,1 & 0 & 542,2 & 208,5 \\
& All & PM10 & $-96,9$ & 194,7 & 12,1 & $-243,9$ & 5,2 & -56 \\
& Cardio & PM10 & $-19,3$ & 36,9 & 2 & $-48,1$ & 0,6 & $-11,2$ \\
& Respiratory & PM10 & $-7,2$ & 15,3 & 1,1 & $-18,4$ & 0,6 & $-4,2$ \\
& All & O3 & $-15,9$ & 54 & 6,8 & $-47,4$ & 22,1 & $-7,9$ \\
& Cardio & O3 & $-4,9$ & 16,6 & 2,1 & $-14,6$ & 6,8 & $-2,4$ \\
& Respiratory & O3 & $-4,1$ & 19,2 & 2,8 & $-14,1$ & 8,3 & $-2,1$ \\
\hline
\end{tabular}

Figure 2 shows the annual total costs due to cardiovascular hospital admissions (morbidity) by changes on PM10 concentrations affected by the global climate change. It is for year 2050 with the RCP 4.5 climate scenario over a zoom-in area de $1 \mathrm{~km}$ by $1 \mathrm{~km}$ of the Milan city. Figure 2 shows how the cost could be incremented in some areas up to $6400 \$$ and in very near areas the climate change will save up to $2800 \$$ in grid cells of 50 meters of spatial resolution because the climate will change the PM10 concentrations. 


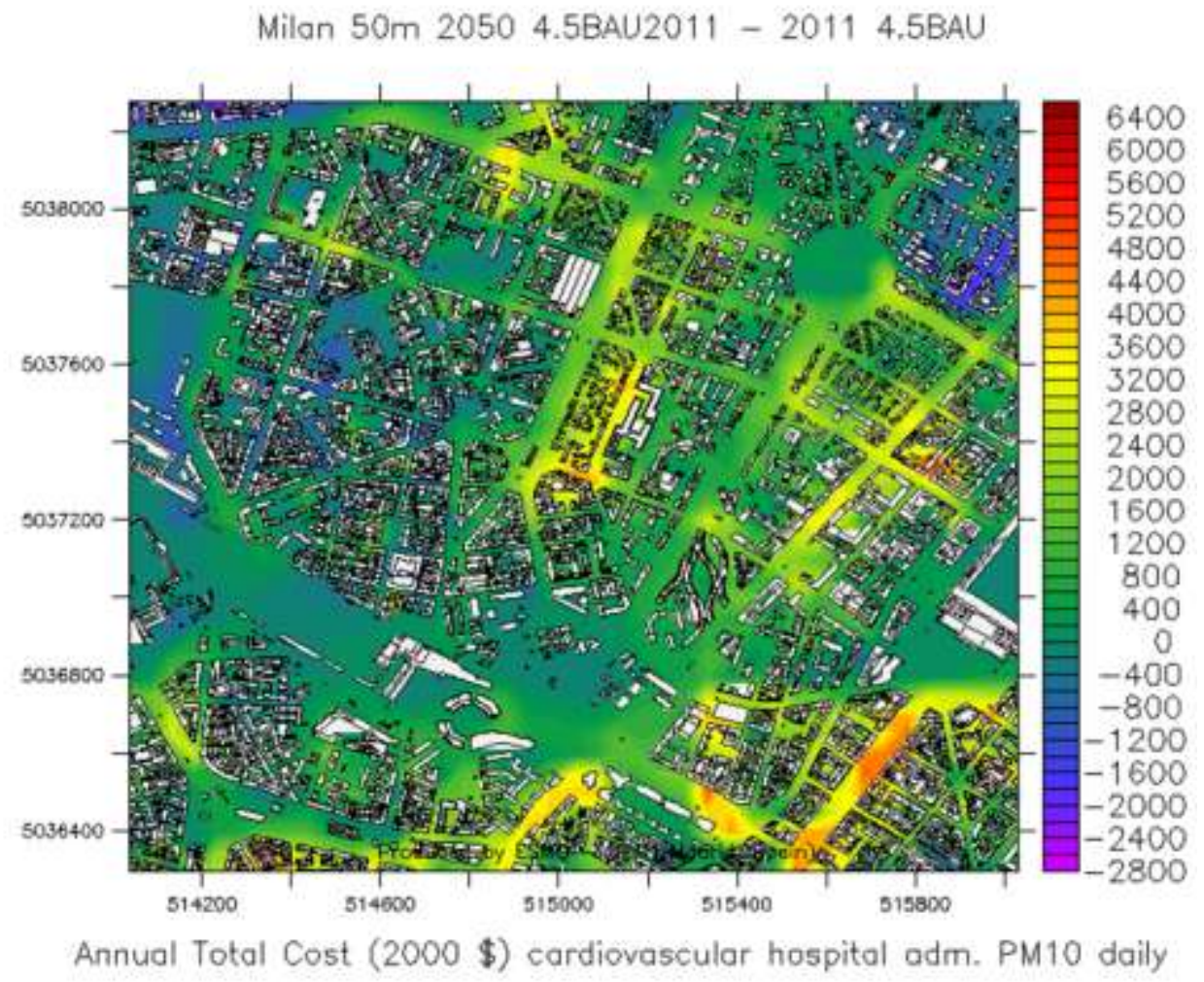

Fig 2: Spatial distribution of the differences in annual total cost (2000 \$) morbidity (cardiovascular hospital admissions) for 2050 respect to 2011 following RCP 4.5 scenario with $50 \mathrm{~m}$. of spatial resolution over $1 \mathrm{~km}$ by $1 \mathrm{~km}$ area of Milan.

In case of Madrid, the health impact assessment was restricted to the heat exposure. The main problem found was the increment of the heat waves in years 2050 and 2100 . This increment will cost in the year 2050: $3768,8 \mathrm{~K} \$ \mathrm{RCP} 4.5$ and 4540 K\$ RCP 8.5 and for the year 2100: $-2206,3$ \$ RCP 4.5 and $10353,3 \mathrm{~K} \$ \mathrm{RCP} 8.5$. The costs are due to mortality of people older than 65 years in an average grid cell of 50 meters by 50 meters. Only the scenario RCP 4.5 in the year 2100 will be reduce the cost of mortality by heat waves respect to the year 2011. Figure 3 shows an example how could be the spatial distributions of the cost of the mortality by heat waves in year 2100 with the climate scenario RCP 8.5 over $1 \mathrm{~km}$ by $1 \mathrm{~km}$ area of Madrid, city center. The figure 3 shows how the impacts of the climate change could be very different between different streets of the city. In this case, an area of $1 \mathrm{~km}$ by 1 $\mathrm{km}$, in the populated zones, the impacts of the climate change will cost between $1.44 \mathrm{~K} \$ / \mathrm{m} 2$ and $0.8 \mathrm{~K} \$ / \mathrm{m} 2$. This is a clear example than the presented tool allows identifying "health hot spots". 


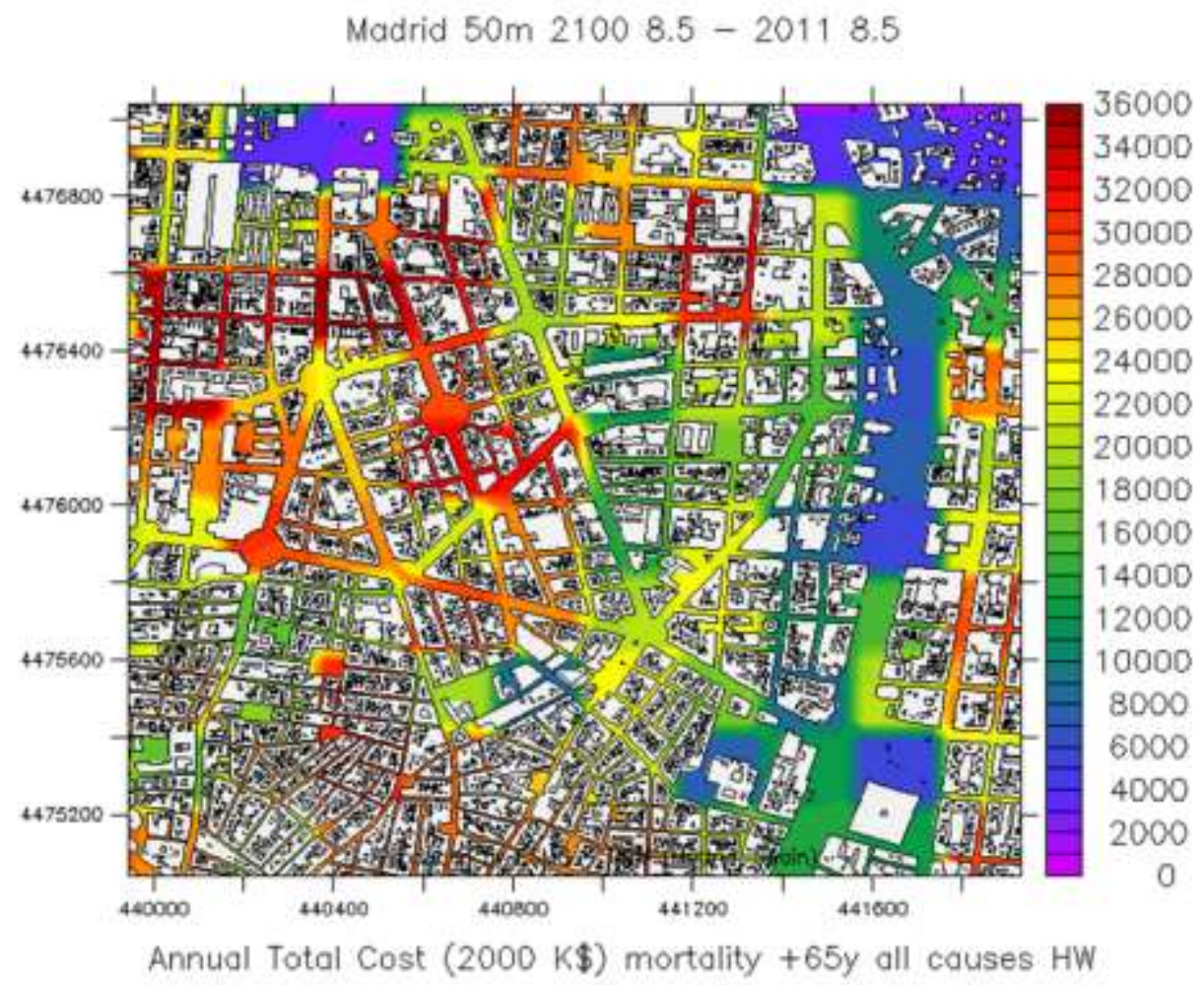

Fig 3: Spatial distribution of the differences in annual total cost (2000 K\$) mortality of people older than 65 by heat waves for 2100 respect to 2011 following RCP 8.5 scenario with $50 \mathrm{~m}$. of spatial resolution over $1 \mathrm{~km}$ by $1 \mathrm{~km}$ area of Madrid.

\section{CONCLUSION}

The purpose of this study was to investigate the cost of the impact of global climate change on human mortality and morbidity by changes of high temperatures and air pollution concentrations for three European cities: Madrid, Milan and London with very high spatial resolution, 50 meters. In this study climate projections were based on two IPCC scenarios: RCP 8.5 and RCP 4.5. Inputs to the health impact assessment have been produced applying a dynamical downscaling process which includes a regional and CFD model with high demand exercise for computational resources. The larger increase of costs of mortality and morbidity was noted in the increasing scenario (RCP8.5) than the stabilization scenario (RCP4.5), because RCP 8.5 is characterized by temperature increments. As summary, Madrid will be the city more affected by the climate change with a cost of the health of 5.35 $\mathrm{K} \$ / \mathrm{m} 2$, the next is Milan $1.65 \mathrm{~K} \$ / \mathrm{m} 2$ and finally London with $0.99 \mathrm{~K} \$ / \mathrm{m} 2$. It is important to recognize that there are many uncertainties in any effort to quantify the human health and economic impacts of climate change over the cities because there are model uncertainties in both economic and atmospheric simulations that are difficult to quantify. The results from this study could be usable by local authorities and stakeholders for assisting in developing better polices on health protections and balancing policy decisions. This study may enhance current understanding of environment problems related to human health in the cities.

\section{ACKNOWLEDGMENT}

The UPM authors acknowledge the computer resources and technical assistance provided by the Centro de Supercomputación y Visualización de Madrid (CeSViMa). The UPM authors thankfully acknowledge the computer resources, technical expertise and assistance provided by the Red Española de Supercomputación.). We acknowledge the DECUMANUS EU project from EU Space Call FP7-SPACE2013-1 at SPA.20131.1-06. Ordnance Survey data for London: (C) Crown copyright and database rights 2015 OS 100021668.

\section{REFERENCES}

[1] M. Medina-Ramón and J. Schwartz, "Temperature, temperature extremes, and mortality: a study of acclimatisation and effect modification in 50 US cities," Occup Environ Med 64:827-833, 2007. https://doi.org/10.1136/oem.2007.033175

[2] S. Hajat and T. Kosatsky, "Heat-related mortality: a review and exploration of heterogeneity," $J$ Epidemiol Community Health 64(9):753-760, 2010. https://doi.org/10.1136/jech.2009.087999

[3] K.W. Oleson,, A Monaghan, O. Wilhelmi, M. Barlage, N. Brunsell , J. Feddema , L. Hu , and D. F. Steinhoff, " Interactions between urbanization, heat stress, and climate change," Climatic Change, 129, 525-541, 2010 https://doi.org/10.1007/s10584-013-0936-8

[4] L.J. Mickley, D.J. Jacob, B.D. Field and D. Rind, "Effects of future climate change on regional air pollution episodes in the United States", Geophys. Res. Let.; 31, L24103, 2004.

[5] M. Valari and L. Menut, "Does an increase in air quality models' resolution bring surface ozone concentrations closer to reality?," $J$. Atmos. Ocean. Tech.; 25, 1955-1968, 2008. https://doi.org/10.1175/2008JTECHA1123.1

[6] HH Shin, DM Stieb, B. Jessiman, MS. Goldberg, O. Brion, J. Brook , T. Ramsay and RT Burnett, "A temporal, multicity model to estimate the effects of short-term exposure to ambient air pollution on health," Environ Health Perspect 116:1147-1153, 2008. https://doi.org/10.1289/ehp.11194 
[7] R. Basu and BD Ostro, "A multicounty analysis identifying the populations vulnerable to mortality associated with high ambient temperature in California," Am J Epidemiol 168:632-637, 2008. https://doi.org/10.1093/aje/kwn170

[8] W. Hu, K. Mengersen, A. McMichael and S. Tong, "Temperature, air pollution and total mortality during summers in Sydney, 1994-2004," Int J Biometeorol 52:689-696, 2008 https://doi.org/10.1007/s00484-008-0161-8

[9] C. Rosenzweig, W Solecki, SA. Hammer and S. Mehrotra, "Cities lead the way in climate-change action," Nature 467: 909-911, 2010. https://doi.org/10.1038/467909a

[10] M. Piringer, E. Petz, I. Groehn, and G. Schauberger , "A sensitivity study of separation distances calculated with the Austrian Odour Dispersion Model (AODM)," Atmospheric Environment, pp.41, 725$1735,2007$.

[11] R. San José, J.L. Pérez, R. M. González, J. Pecci and A. Garzón, M. Palacios, "Impacts of the 4.5 and 8.5 RCP global climate scenarios on urban meteorology and air quality: Application to Madrid, Antwerp, Milan, Helsinki and London, “ Journal of Computational and Applied Mathematics, V 293, February 2016, PP 192-207, ISSN 0377-0427.

[12] G. Hutton, "The economics of health and climate change: key evidence for decision making," Global Health 7:18, 2011. https://doi.org/10.1186/1744-8603-7-18

[13] R. José, J. Pérez, L. Pérez, R. González , J. Pecci, A. Garzón and M. Palacios, "Impacts on the Urban Air Quality and Health of Global Climate Scenarios Using Different Dynamical Downscaling Approaches," Journal of Geoscience and Environment Protection, 4, $168-174,2016$ https://doi.org/10.4236/gep.2016.44020

[14] KL. Ebi and G. McGregor, "Climate change, tropospheric ozone and particulate matter, and health impacts," Environ Health Perspect. 2008;116:1449-1455. https://doi.org/10.1289/ehp.11463

[15] IPCC. Climate Change, "The Physical Science Basis," Cambridge University Press: Cambridge, UK; New York, NY, USA, 2013

[16] A.M. Thomson and Coauthors, "RCP4.5: a pathway for stabilization of radiative forcing by 2100," Clim. Change, 109, 77-94, 2011. https://doi.org/10.1007/s10584-011-0151-4

[17] K. Riahi and Coauthors, " RCP 8.5-A scenario of comparatively high greenhouse gas emissions," Clim. Change, 109, 33-57, 2011. https://doi.org/10.1007/s10584-011-0149-y

[18] HH. Chang, J. Zhou and M. Fuentes, "Impact of climate change on ambient ozone level and mortality in Southeastern United States," Int J Environ Res Public Health. 2010;7:2866-2880 https://doi.org/10.3390/ijerph7072866

[19] PE Sheffield, K. Knowlton, JL. Carr, PL. Kinne, " Modeling of regional climate change effects on ground-level ozone and childhood asthma," Am J Prev Med. 2011;41(3):251-257. https://doi.org/10.1016/j.amepre.2011.04.017

[20] D.P. Vuuren and Coauthors, "The representative concentration pathways: an overview," Clim. Change, 109, 5-31, 2011. https://doi.org/10.1007/s10584-011-0148-z 